\title{
The anterior cingulate gyrus and the mechanism of self-regulation
}

\author{
Michael I. Posner, Mary K. Rothbart, ANd BRad E. Sheese \\ University of Oregon, Eugene, Oregon \\ AND \\ YIYUAN TANG \\ Dalian University of Technology, Dalian, China \\ and University of Oregon, Eugene, Oregon
}

\begin{abstract}
The midfrontal cortex, and particularly the anterior cingulate gyrus, appears active in many studies of functional imaging. Various models have competed to explain the functions of the anterior cingulate in relation to its patterns of activation. We believe that the concept of self-regulation is valuable in considering the role of the cingulate. The sensitivity of the cingulate to both reward and pain, and evidence for cingulate coupling to cognitive and emotional areas during task performance, support this identification. Self-regulation is a very broad concept that does not lend itself very well to specific models or tests, but it does provide a framework for examining development. We trace the role of the midfrontal cortex in evolution and infant development. Both genes and environment influence self-regulation. The presence of both genetic and environmental effects raises the issue of their interaction, which we discuss in relation to the dopamine 4 receptor gene and parenting methods. The role of the midfrontal cortex in self-regulation allows us to consider both brain networks common to all people and network efficiency underlying individual differences in behavior.
\end{abstract}

What do the perception of pain, either physical (Rainville, Duncan, Price, Carrier, \& Bushnell, 1997) or social (Eisenberger, Lieberman, \& Williams, 2003), processing of reward (Hampton \& O'Doherty, 2007), monitoring of conflict (Botvinick, Braver, Barch, Carter, \& Cohen, 2001), error detection (Dehaene, Posner, \& Tucker, 1994), and theory of mind (Kampe, Frith, \& Frith, 2003) all have in common? They all activate an area of midfrontal cortex that includes the anterior cingulate gyrus. Is there a single function that requires all of these important input signals? We have argued that the role of this brain area is to regulate the processing of information from other networks, serving as a part of an executive attention network involved in the control of both cognition and emotion. Executive attention is a brain network that includes the anterior cingulate cortex (ACC) and in adult studies is often activated by requiring a person to withhold a dominant response in order to perform a subdominant response (Posner \& Rothbart, 2007a, 2007b). In developmental psychology, the ability to control our thoughts, feelings, and behavior is called self-regulation. This is a broad function, and one that does not lend itself easily to test or model. However, the self-regulatory view fits well with the evidence of brain activation, functional and structural connectivity, and individual differences. Moreover, the self-regulatory view helps us understand how brain networks relate to important real-life functions.
In this article, we first consider evidence relating the midfrontal cortex, and particularly the ACC, to selfregulation. We then discuss the origins of self-regulation during infancy, and finally examine the role of genes and experience in building the network underlying selfregulation.

\section{Self-Regulation and the ACC}

Self-regulation is a central concept in developmental psychology and in the study of psychopathologies (Fonagy \& Target, 2002). In our view, self-regulation is a natural function of brain networks, designed to control the influx of information from the environment through orienting, in order to avoid conflicting responses in behavior (Rueda, Posner, \& Rothbart, 2004). A good example is the Stroop effect, in which word reading is a highly overlearned response that must be ignored in order to respond with the conflicting ink color. Neuroimaging presents strong evidence that conflict tasks like the Stroop effect activate common areas of the anterior cingulate gyrus (Botvinick et al., 2001; Bush, Luu, \& Posner, 2000; Fan, Flombaum, McCandliss, Thomas, \& Posner, 2003).

Support for the voluntary exercise of self-regulation comes from studies that examine either the instruction to control affect or the connections involved in the exercise of that control. For example, the instruction to avoid

M. I. Posner, mposner@uoregon.edu 
arousal during processing of erotic events (Beauregard, Levesque, \& Bourgouin, 2001) or to ward off emotion when looking at negative pictures (Ochsner et al., 2001) produces a locus of activation in midfrontal and cingulate areas. If people are required to select an input modality, the cingulate shows functional connectivity to the selected sensory system (Crottaz-Herbette \& Menon, 2006). Similarly, when involved with emotional processing, the cingulate shows a functional connection to limbic areas (Etkin, Egner, Peraza, Kandel, \& Hirsch, 2006). These findings support the role of cingulate areas in the control of cognition and emotion. There is also evidence for anatomical connectivity between the ventral cingulate and limbic areas and the dorsal cingulate, parietal, and frontal areas (Posner, Sheese, Odludas, \& Tang, 2007).

The ACC is a phylogenetically old area of the brain. Comparative anatomical studies point to important differences in the evolution of cingulate connectivity between nonhuman primates and humans. Anatomical studies show the great expansion of white matter, which has increased more in recent evolution than has the neocortex itself (Zilles, 2005). One type of projection cell, called the Von Economo neuron, is found only in the anterior cingulate and a related area of the anterior insula (Allman, Watson, Tetreault, \& Hakeem, 2005). The two brain areas in which Von Economo neurons are found (cingulate and anterior insula) are also shown to be in close communication during the resting state (Dosenbach et al., 2007). It is thought that this neuron is important in communication between the cingulate and other brain areas. This neuron is not present at all in macaques, and expands greatly in frequency between great apes and humans. Moreover, there is some evidence that the frequency of this type of neuron also increases in development between infancy and later childhood (Allman et al., 2005). In our view, these neurons - and the rapid and efficient connectivity they provide - are a major reason why self-regulation in adult humans can be so much stronger than in other organisms.

\section{Origins of Self-Regulation}

A number of investigators have traced the development of attention and self-regulation during childhood (see, e.g., Davidson, Amso, Anderson, \& Diamond, 2006; Posner \& Rothbart, 2007a). The presence of machinery for self-regulation in some primates suggests that it should be found in infancy as well. Most of the study of the development of self-regulation has involved children of age 3 or older who are able to follow instructions used in tasks such as those involving conflict.

We have been especially interested in the origins of self-regulation in infancy. Studies by Diamond (1990) and Wynn (1992) found that infants can control their reaching toward objects and detect error. We (Posner \& Rothbart, 2007a) have been interested in determining whether the executive attention network that includes the midfrontal cortex is involved in this function during infancy. The development of executive attention can be observed easily, using both questionnaires and cognitive tasks, after about age 3-4, when parents can identify the ability of their children to regulate their emotions and control their behavior in accord with social demands. However, in infancy, it has been difficult to pose questions that refer to effortful control, because most regulation seems automatic or involves the caregiver's intervention. Obviously, infants cannot be instructed to press a key in accord with a particular rule.

Infant studies. Error detection is one way to study selfregulation. We (Berger, Tzur, \& Posner, 2006) examined the ability of 7-month-old infants to detect error. Infants observed a scenario in which one or two puppets were hidden behind a screen. A hand was seen to reach behind the screen and either add or remove a puppet. When the screen was removed, either the correct number of puppets or an incorrect number was revealed. Wynn (1992) found that 7-month-old infants looked longer when the number was in error than when it was correct. Whether the increased looking time involved the same executive attention circuitry that was active in adults was unknown. Berger et al. replicated the Wynn study but used 128-channel EEG to compare the brain activity that occurred during error trials with the activity involved when the infant viewed a correct solution. The results indicated that the same EEG component over the same electrode sites differed between correct and error trials in infants and adults. Since this EEG component had been shown to come from the anterior cingulate gyrus (Dehaene et al., 1994), it appears that the same brain anatomy is involved in infant error detection as has been found in adult studies. Of course, the result of activating this anatomy for observing an error is not the same as has been found in adults for self-made errors, where the adults actually slow down after an error and adjust their performance. However, it suggests that even very early in life, the anatomy of the executive attention system is at least partly in place.

We also began a longitudinal study with 7-month-old infants (Sheese, Rothbart, Posner, White, \& Fraundorf, 2007). We studied eye movements that occurred when attractive stimuli appeared in a fixed sequence of locations on a screen in front of the child. On most occasions, the children moved their eyes to the stimulus, but on some occasions, they moved their eyes to the location where the stimulus would occur prior to its being presented (anticipation). We believe that the anticipatory movements were an early form of voluntary response, because they actually anticipated the visual event. We previously found that 3.5-year-olds showed a correlation between performance on conflict trials in a voluntary keypress task and the tendency to make correct anticipations when in the visual sequence task (Rothbart, Ellis, Rueda, \& Posner, 2003).

In the first session of our longitudinal study, we examined how frequency of anticipatory movements in the visual sequence task was related to self-regulation during the presentation of novel toys and the presentation of a frightening mask. Anticipatory looking was related to more hesitant initial approach to the toys, including longer latencies to initial reaching and longer duration of looking without physically touching the toy. This result was particularly interesting because anticipatory looks have extremely short latencies with respect to the stimulus (either before the stimulus or within $130 \mathrm{msec}$ ), yet they are associated with long latencies in reaching for the toy. The controlled reach 
is probably of importance in the development of the ability to reach to locations other than along the line of sight that has been traced in infancy (Diamond, 1990).

Anticipatory looking was also positively related to greater use of sucking as a self-soothing mechanism during the presentation of masks that caused emotional disturbance. These results indicate that anticipatory looking is related both to caution in reaching toward novel toys, and to aspects of the regulation of distress in infancy. They also suggest that executive attention is present in infancy and serves as one basis for the regulation of emotion.

\section{Individuality}

Individual differences in self-regulation emerge as a factor in parent-report studies of temperament in children who are about age 3 (Rothbart \& Rueda, 2005). Effortful control (EC) is defined as the ability to control responses so as to withhold a dominant response tendency while making a subdominant response. At this age, it involves subscales of attention focusing, attention shifting, inhibitory control, and perceptual sensitivity that all load on a common effortful control factor (Rothbart \& Rueda, 2005).

At age 3, one can also use voluntary keypress tasks, which require the child to resolve conflict. In adults, a number of conflict-related tasks have been shown to activate a common brain network that includes the anterior cingulate cortex and lateral prefrontal areas (Fan, Flombaum, McCandliss, Thomas, \& Posner, 2003). One such conflict task appropriate for 3-year-olds involves a spatial conflict between the identity of an object and its location. A target object is displayed on a screen, and the child must press a key that has a picture of the identical object, but the key may be located on the same side as the target (congruent) or on the opposite side (incongruent). Gerardi-Caulton (2000) found the performance in a spatial conflict task was related to this higher order EC factor. Similar findings linking parent-reported temperament EC to performance on laboratory attention tasks have been shown with 24-, 30-, and 36-month-olds (Rothbart, Ellis, \& Posner, 2004), 3 - and 5-year-olds (Chang \& Burns, 2005), and 7-yearolds (González, Fuentes, Carranza, \& Estévez, 2001).

$\mathrm{EC}$ has also been linked to the brain areas involved in self-regulation by imaging studies (Whittle, 2007). Whittle had 155 adolescents fill out a temperament scale (Ellis \& Rothbart, 2001) and also measured the size of different brain structures and their activity. She found that dorsal anterior cingulate size was positively correlated to EC and that ventral anterior cingulate activity was negatively related to EC. The reciprocal relation between the ventral and dorsal cingulate has also been reported in other imaging studies (Drevets \& Raichle, 1998).

$\mathrm{EC}$ and executive attention scores have been related to many aspects of child development. EC is related to the empathy that children show toward others, their ability to delay an action, and their ability to avoid such behaviors as lying or cheating, when given the opportunity in laboratory studies (Rothbart \& Rueda, 2005). There is also evidence that high levels of EC and good ability to resolve conflict are related to fewer antisocial behaviors, such as truancy, in adolescents (Ellis, Rothbart, \& Posner, 2004).

\section{Genes and Network Development}

As more is known about the developmental progression of executive attention (Posner \& Rothbart, 2007a), there is an increased possibility of accounting for both the general development of the network and individual differences by examining how genes and experience interact to shape the executive attention network.

To determine genes that might be related to building an attentional network, we used the Attention Network Test (ANT) to examine individual differences in the efficiency of executive attention. The ANT (Fan, McCandliss, Sommer, Raz, \& Posner, 2002) uses cues to indicate when and where a target might occur. The target is a central arrow that points left or right, and the person is instructed to respond with the key in the direction of the arrow. Flankers can be either congruent or incongruent with the arrow, thus introducing conflict. Subtraction of RTs to cue or target conditions is used to measure the efficiency of alerting (no cue - double cue), orienting (cue at target - central cue), or executive attention (incongruent flankers - congruent flankers).

We first used the ANT in genetic studies to assess attention in monozygotic and dizygotic same-sex twins (Fan, $\mathrm{Wu}$, Fossella, \& Posner, 2001). We found strong heritability of the executive network. These data supported a search for genes related to executive attention.

We then used the association of the executive network with the neuromodulator dopamine as a way of searching for candidate genes that might relate to the efficiency of the network (Fossella et al., 2002). To do this, 200 persons performed the ANT and were genotyped to examine frequent polymorphisms in genes related to dopamine. We found significant association of two genes, the dopamine D4 receptor (DRD4) gene and the monoamine oxidase a (MAOA) gene, with executive attention. We then conducted a neuroimaging experiment in which persons with different alleles of these two genes were compared while they performed the ANT (Fan, Fossella, Sommer, \& Posner, 2003). Groups with different alleles of these genes showed differences in the ability to resolve conflict as measured by the ANT, and produced significantly different activations in the anterior cingulate, a major node of the executive attention network.

Recent studies have extended these observations. In two different studies employing conflict-related tasks other than the ANT, alleles of the catechol-o-methyl transferase (COMT) gene were related to the ability to resolve conflict (Blasi et al., 2005; Diamond, Briand, Fossella, \& Gehlbach, 2004). A study using the child ANT showed a significant relation between the DAT1 and executive attention as measured by the ANT (Rueda, Rothbart, McCandliss, Saccomanno, \& Posner, 2005). In addition, research has suggested that genes related to serotonin transmission also influence executive attention (Canli et al., 2005; Reuter, Ott, Vaitl, \& Hennig, 2007). Future studies should determine other genetic influences and examine their interaction and modes of operation.

The relation of genetic factors to the functioning of the executive attention system does not mean that the system cannot be influenced by experience. Rather, it appears 
that some genetic variation allows for additional influence from parenting and other experiences (Sheese, Voelker, Rothbart, \& Posner, in press). We found that the 7 repeat allele of the DRD4 receptor gene interacted with the quality of parenting to influence such temperamental variables in the child as activity level, sensation seeking, and impulsivity. Other research has shown similar findings for externalizing behavior of the child, as rated by the parents in the Child Behavior Checklist (Bakermans-Kranenburg \& van IJzendoorn, 2006). There is evidence that the 7 repeat allele of the DRD4 gene is under positive selective pressure (Ding et al., 2002). Our results suggest that a possible reason for this finding is that genetic variation makes it more likely that children will be influenced by their culture through parenting style. This idea could be important for understanding the principles of why the frequency of genetic alleles changes during human evolution.

Genes do not directly produce attention. What they do is code for different proteins that influence the efficiency with which modulators such as dopamine are produced and/or bind to their receptors. These modulators are in turn related to individual differences in the efficiency of the attention networks. There is a great deal in common among humans in the anatomy of high-level networks, and this must have a basis within the human genome. The same genes that are related to individual differences in attention are also likely to be important in the development of the attentional networks that are common to all humans. Some of these networks are also common to nonhuman animals. By examining these networks in animals, it should be possible to better understand the role of genes in shaping networks.

Can animals perform the same tasks we have developed for humans? The answer is clearly yes. Monkeys have been trained to shift attention to cues and to carry out conflict tasks like those in the ANT. More recently, rodents have also been trained in attention-shifting tasks (Beane \& Marrocco, 2004). These tasks make it possible to examine the role that genes play in carrying out the same attentional operations as have been studied in humans. It has also been reported that areas of the frontal midline corresponding to the anterior cingulate are activated in the mouse during trace but not delayed conditioning (Han, O'Tuathaigh, \& Koch, 2004). Since trace and delayed conditioning are both very simple tasks, and the two are quite similar, they could be used to measure operation of rodent brain areas that may be related to executive attention in humans.

An important need in this effort is the development of methods to manipulate relevant genes in specific anatomical locations that are important nodes of a particular network. Usually, genes are expressed at multiple locations, so that changes (e.g., knock-out studies) are not specific to one brain area. Subtractive genomics is a method currently being developed (Dumas et al., 2005) to manipulate genes at a specific anatomical location. This method is now being employed to manipulate the DRD4 gene within the midfrontal cortex of the mouse. It should become possible to determine the specific operations performed by genes at particular locations in attentional networks. We believe that this kind of genetic analysis of network development will create a productive link between genes and the development of the networks involved in selfregulation (Posner \& Rothbart, 2007b).

The self-regulation idea is closely related to many more formal theories of the role of the midfrontal cortex. Since regulation is most needed when there is conflict between activity in different brain areas, the regulation viewpoint suggests that the monitoring and/or resolution of conflict would activate this area (Botvinick et al., 2001). Since error correction is an important aspect of self-regulation, the midfrontal cortex would also need to know about the occurrence of error, either directly or through feedback (Dehaene et al., 1994). Obviously, the reward (Hampton \& O'Doherty, 2007) or punishment value of stimuli (Rainville et al., 1997) would be important in how to resolve conflicts, and thus, self-regulation implies the need for information on the reward or punishment associated with cues. The voluntary aspect of much of self-regulation also fits quite well in the decision-making view of midfrontal cortex (Botvinick, 2007). In addition, viewing the midfrontal cortex as part of the mechanism of self-regulation seems to us to provide a useful framework for examining how genes and experience shape the shifts in behavior seen during early development.

\section{AUTHOR NOTE}

This research was supported by NIMH Grant HD5801 to Georgia State University and by a grant from the Dana Foundation for the study of the arts. Correspondence concerning this article should be addressed to M. I. Posner, Department of Psychology, 1227 University of Oregon, Eugene, OR 97403-1227 (e-mail: mposner@uoregon.edu).

\section{REFERENCES}

Allman, J. M., Watson, K. K., Tetreault, N. A., \& Hakeem, A. Y. (2005). Intuition and autism: A possible role for Von Economo neurons. Trends in Cognitive Science, 9, 367-373.

Bakermans-Kranenburg, M. J., \& VAN IJZEndoorn, M. H. (2006). Gene-environment interaction of the dopamine D4 receptor (DRD4) and observed maternal insensitivity predicting externalizing behavior in preschoolers. Developmental Psychobiology, 48, 406-409.

Beane, M., \& Marrocco, R. (2004). Cholinergic and noradrenergic inputs to the posterior parietal cortex modulate the components of exogenous attention. In M. I. Posner (Ed.), Cognitive neuroscience of attention (pp. 313-325). New York: Guilford.

Beauregard, M., Levesque, J., \& Bourgouin, P. (2001). Neural correlates of conscious self-regulation of emotion. Journal of Neuroscience, 21, RC165.

Berger, A., Tzur, G., \& Posner, M. I. (2006). Infant brains detect arithmetic errors. Proceedings of the National Academy of Sciences, 103, 12649-12653.

Blasi, G., Mattay, V. S., Bertolino, A., Elvevåg, B., Callicott, J. H., DAs, S., ET AL. (2005). Effect of catechol-o-methyltransferase $\mathrm{val}^{158}$ met genotype on attentional control. Journal of Neuroscience, 25, 5038-5045.

BotvinicK, M. M. (2007). Conflict monitoring and decision making: Reconciling two perspectives on anterior cingulate function. Journal of Cognitive, Affective, \& Behavioral Neuroscience, 7, 356-366.

Botvinick, M. M., Braver, T. S., Barch, D. M., Carter, C. S., \& Cohen, J. D. (2001). Conflict monitoring and cognitive control. Psychological Review, 108, 624-652.

Bush, G., Luu, P., \& Posner, M. I. (2000). Cognitive and emotional influences in anterior cingulate cortex. Trends in Cognitive Sciences, 4, 215-222.

Canli, T., Omura, K., Haas, B. W., Fallgatter, A., Todd, R., Con- 
Stable, R. T., \& Lesch, K. P. (2005). Beyond affect: A role for genetic variation of the serotonin transporter in neural activation during a cognitive attention task. Proceedings of the National Academy of Sciences, 102, 12224-12229.

Chang, F., \& Burns, B. M. (2005). Attention in preschoolers: Associations with effortful control and motivation. Child Development, 76, 247-263.

Crottaz-Herbette, S., \& Menon, V. (2006). Where and when the anterior cingulate cortex modulates attentional response: Combined fMRI and ERP evidence. Journal of Cognitive Neuroscience, 18, 766-780.

Davidson, M. C., Amso, D., Anderson, L. C., \& Diamond, A. (2006) Development of cognitive control and executive functions from 4 to 13 years: Evidence from manipulations of memory, inhibition, and task switching. Neuropsychologia, 44, 2037-2078.

Dehaene, S., Posner, M. I., \& Tucker, D. M. (1994). Localization of a neural system for error detection and compensation. Psychological Science, 5, 303-305.

Diamond, A. (1990). Developmental time course in human infants and infant monkeys and the neural basis of inhibitory control in reaching. Annals of the New York Academy of Sciences, 608, 637-676.

Diamond, A., Briand, L., Fossella, J., \& Gehlbach, L. (2004). Genetic and neurochemical modulation of prefrontal cognitive functions in children. American Journal of Psychiatry, 161, 125-132.

Ding, Y. C., Chi, H. C., Grady, D. L., Morishima, A., Kidd, J. R., KIDD, K. K., ET AL. (2002). Evidence of positive selection acting at the human dopamine receptor D4 gene locus. Proceedings of the $\mathrm{Na}$ tional Academy of Sciences, 99, 309-314.

Dosenbach, N. U. F., Fair, D. A., Miezin, F. M., Cohen, A. L., Wenger, K. K., Dosenbach, R. A. T., et AL. (2007). Distinct brain networks for adaptive and stable task control in humans, Proceedings of the National Academy of Sciences, 104, 11073-11078.

Drevets, W. C., \& Raichle, M. E. (1998). Reciprocal suppression of regional blood flow during emotional versus higher cognitive processes: Implications for interactions between emotion and cognition. Cognition \& Emotion, 12, 353-385.

Dumas, T., Hostick, U., Wu, H., Spaltenstein, J., Ghatak, C., Nguyen, J., \& Kentros, C. (2005). Maximizing the anatomical specificity of native neuronal promoters by a subtractive transgenic technique. Society for Neuroscience Abstracts, No. 228.6. Online.

Eisenberger, N. I., Lieberman, M. D., \& Williams, K. D. (2003). Does rejection hurt? An fMRI study of social exclusion. Science, 302, 290-292.

Ellis, L. K., \& Rothbart, M. K. (2001). Revision of the early adolescent temperament questionnaire. Paper presented at the 2001 meeting of the Society for Research in Child Development, Minneapolis, Minnesota.

Ellis, L. K., Rothbart, M. K., \& Posner, M. I. (2004). Individual differences in executive attention predict self-regulation and adolescent psychosocial behaviors Annals of the New York Academy of Sciences, 1031, 337-340.

Etkin, A., Egner, T., Peraza, D. M., Kandel, E. R., \& Hirsch, J. (2006). Resolving emotional conflict: A role for the rostral anterior cingulate cortex in modulating activity in the amygdala. Neuron, 51, 871-882.

Fan, J., Flombaum, J. I., McCandliss, B. D., Thomas, K. M., \& PosNER, M. I. (2003). Cognitive and brain consequences of conflict. NeuroImage, 18, 42-57.

Fan, J., Fossella, J. A., Sommer, T., \& Posner, M. I. (2003). Mapping the genetic variation of executive attention onto brain activity. Proceedings of the National Academy of Sciences, 100, 7406-7411.

Fan, J., McCandliss, B. D., Sommer, T., Raz, A., \& Posner, M. I. (2002). Testing the efficiency and independence of attentional networks. Journal of Cognitive Neuroscience, 14, 340-347.

Fan, J., Wu, Y., Fossella, J., \& Posner, M. I. (2001). Assessing the heritability of attentional networks. BMC Neuroscience, 2, 14.

FonAGy, P., \& TARGET, M. (2002). Early intervention and the development of self-regulation. Psychoanalytic Inquiry, 22, 307-335.

Fossella, J., Sommer, T., Fan, J., Wu, Y., Swanson, J. M., Pfaff, D. W., \& Posner, M. I. (2002). Assessing the molecular genetics of attention networks. BMC Neuroscience, $\mathbf{3}, 14$.

Gerardi-Caulton, G. (2000). Sensitivity to spatial conflict and the development of self-regulation in children 24-36 months of age. Developmental Science, 3, 397-404.

González, C., Fuentes, L. J., Carranza, J. A., \& Estévez, A. F. (2001). Temperament and attention in the self-regulation of 7-year-old children. Personality \& Individual Differences, 30, 931-946.

Hampton, A. N., \& O'Doherty, J. P. (2007). Decoding the neural substrates of reward-related decision making with functional MRI. Proceedings of the National Academy of Sciences, 104, 1377-1382.

Han, C. J., O'Tuathaigh, C. M., \& Koch, C. (2004). A practical assay for attention in mice. In M. I. Posner (Ed.), Cognitive neuroscience of attention (pp. 294-312). New York: Guilford.

Kampe, K. K. W., Frith, C. D., \& Frith, U. (2003). "Hey John”: Signals conveying communicative intention toward the self activate brain regions associated with "mentalizing," regardless of modality. Journal of Neuroscience, 23, 5258-5263.

Ochsner, K. N., Kossyln, S. M., Cosgrove, G. R., Cassem, E. H., Price, B. H., NierenberG, A. A., \& Rauch, S. L. (2001). Deficits in visual cognition and attention following bilateral anterior cingulotomy. Neuropsychologia, 39, 219-230.

Posner, M. I., \& Rothbart, M. K. (2007a). Educating the human brain. Washington, DC: American Psychological Association.

Posner, M. I., \& Rothbart, M. K. (2007b). Research on attention networks as a model for the integration of psychological science. Annual Review of Psychology, 58, 1-23.

Posner, M. I., Sheese, B. E., Odludas, Y., \& Tang, Y. (2007). Analyzing and shaping neural networks. Neural Networks, 19, 1422-1429.

Rainville, P., Duncan, G. H., Price, D. D., Carrier, B., \& BushNELL, M. C. (1997). Pain affect encoded in human anterior cingulate but not somatosensory cortex. Science, 277, 968-971.

Reuter, M., Ott, U., Vaitl, D., \& Hennig, J. (2007). Impaired executive control is associated with a variation in the promoter region of the tryptophan hydroxylase 2 gene. Journal of Cognitive Neuroscience, 19, 401-408.

Rothbart, M. K., Ellis, L. K., \& Posner, M. I. (2004). Temperament and self-regulation. In R. F. Baumeister \& K. D. Vohs (Eds.), Handbook of self-regulation: Research, theory, and applications (pp. 357370). New York: Guilford.

Rothbart, M. K., Ellis, L. K., Rueda, M. R., \& Posner, M. I. (2003). Developing mechanisms of temperamental effortful control. Journal of Personality, 71, 1113-1143.

Rothbart, M. K., \& RuEda, M. R. (2005). The development of effortful control. In U. Mayr, E. Awh, \& S. W. Keele (Eds.), Developing individuality in the human brain: A tribute to Michael I. Posner (pp. 167188). Washington, DC: American Psychological Association.

Rueda, M. R., Posner, M. I., \& Rothbart, M. K. (2004). Attentional control and self-regulation. In R. F. Baumeister \& K. D. Vohs (Eds.), Handbook of self-regulation: Research, theory, and applications (pp. 283-300). New York: Guilford.

Rueda, M. R., Rothbart, M. K., McCandliss, B. D., SaccoMANno, L., \& Posner, M. I. (2005). Training, maturation, and genetic influences on the development of executive attention. Proceedings of the National Academy of Sciences, 102, 14931-14936.

Sheese, B. E., Rothbart, M. K., Posner, M. I., White, L. K., \& FRAUNDORF, S. H. (2007). Executive attention and self-regulation in infancy. Manuscript submitted for publication.

Sheese, B. E., Voelker, P., Rothbart, M. K., \& Posner, M. I. (in press). Caregiver quality interacts with genetic variation to influence aspects of toddler temperament. Development \& Psychopathology.

WhitTLE, S. L. (2007). The neurobiological correlates of temperament in early adolescents. Unpublished doctoral dissertation, University of Melbourne, Australia.

WyNN, K. (1992). Addition and subtraction by human infants. Nature, 358, 749-750.

ZILLES, K. (2005). Evolution of the human brain and comparative cyto- and receptor architecture. In S. Dehaene, J.-R. Duhamel, M. D. Hauser, \& G. Rizzolatti (Eds.), From monkey brain to human brain (pp. 41-56). Cambridge, MA: MIT Press, Bradford Books.

(Manuscript received March 6, 2007; revision accepted for publication July 26, 2007.) 